\title{
New York State Partnerships in Employment
}

\author{
Julie J. Christensen ${ }^{\mathrm{a}, *}$, Kaitlyn Richardson ${ }^{\mathrm{b}}$ and Susan Hetherington ${ }^{\mathrm{b}}$ \\ ${ }^{a}$ University of Iowa Hospitals and Clinics, Center for Disabilities and Development, Iowa City, IA, USA \\ ${ }^{\mathrm{b}}$ University of Rochester Medical Center, Strong Center for Developmental Disabilities, Rochester, NY, USA
}

Revised/Accepted April 2017

\begin{abstract}
.
BACKGROUND: The New York State Partnerships in Employment Systems Change project (NYS PIE) was a statewide initiative aimed at developing and sustaining systemic activities and policies that improve opportunities for competitive, integrated employment for transition-aged youth and young adults with intellectual and/or developmental disabilities (IDD). Specifically, the goal of NYS PIE was to promote an Employment First platform in NYS making competitive, integrated employment the first choice in coordinating service delivery for young people with IDD.

OBJECTIVE: This articles describes the characteristics and impact of NYS PIE on the state of New York.

CONCLUSION: The NYS PIE project utilized a cross-systems approach, grounded in the principles of the Collective Impact model, to bring together systems that have not traditionally, nor consistently, collaborated or communicated with one another. Focusing on the shared goals of improving quality of life and independence of New Yorkers with disabilities, the project aimed to increase the level of communication and collaboration between education, vocational rehabilitation and the state DD agency at state, regional and local levels. Project activities focused on building capacity around sustainable models that ensure employment preparation begins early in a student's high school career, that students have opportunities to work in the community prior to graduation, and that young adults in segregated work environments are encouraged and supported to transition to work and careers in the community.
\end{abstract}

Keywords: Transition, integrated employment, youth with disabilities, young adults with disabilities, intellectual disability, developmental disability, systems change, collective impact

\section{Introduction}

The New York State Partnerships in Employment Systems Change project (NYS PIE), which was funded from 2011-2016, aimed to promote an Employment First philosophy in NYS that would result in improved quality of life and independence for people with disabilities. More specifically, the goal was to develop and sustain systemic activities and policies that improve opportunities for competitive, integrated employment for youth and young adults with intellectual and/or developmental disabilities (IDD).

\footnotetext{
*Address for correspondence: Julie J. Christensen, MSW, PhD, University of Iowa, Center for Disabilities and Development, 100 Hawkins Drive, Iowa City, IA 52242, USA. Tel.: +1 319384 5934; E-mail: Julie-Christensen@uiowa.edu.
}

The New York State (NYS) plan utilized a crosssystems approach and promoted a strategy whereby all stakeholders were required to embrace competitive, integrated employment as the first choice when coordinating service delivery for young people with IDD. It was also based on an understanding that effective preparation begins early in a student's high school career; that students need employment opportunities prior to graduation; and that young adults in segregated work environments must be provided supported opportunities to move into competitive, integrated employment through access to appropriate educational and vocational training programs. Without this understanding, an improved quality of life and independence were at risk.

NYS is a large and complex state with a population of over 19 million people. At the start of the NYS 
PIE effort in 2011, it was estimated that there were 1.4 million working-aged adults with disabilities living in communities across the state, with approximately 445,000 having a developmental disability (Rehabilitation Research and Training Center on Disability Statistics and Demographics, 2009). While unemployment rates in NYS were uniformly high, it is notable that the employment rate for individuals with disabilities was just $34 \%$, compared to $76 \%$ for people without disabilities, when this initiative began; while New Yorkers with intellectual disabilities were employed at a rate of $25 \%$ (Von Schrader, Erickson, Vilhuber \& Golden, 2010).

To positively impact employment outcomes for New Yorkers with disabilities, including people with IDD, the NYS PIE project required work at the local, regional and state levels. Project activities aimed to build enhanced cross-systems collaboration, strong youth and young adult self-advocacy communities, and engaged partnerships with businesses committed to hiring people with disabilities.

However, at the start of this effort, the key state agencies supporting individuals with disabilities in NYS did not have a consistent history of collaboration or communication with one another. The NYS PIE project thus aimed to increase the level of communication and collaboration among these agencies both at the state and local levels of agency leadership. All project activities were designed to inform state agency priorities and practices resulting in coordinated systems change on a state level.

\subsection{Project goals}

This NYS PIE project aimed to establish state partnerships and systems change efforts that would ultimately contribute to:

1. Promoting an Employment First philosophy leading to improved quality of life and independence for all New Yorkers with disabilities;

2. Developing policies and regulatory practices that support competitive, integrated employment as the first and desired outcome for youth and young adults with intellectual and developmental disabilities (IDD);

3. Removing systemic barriers to competitive integrated employment;

4. Implementing strategies and best practices that lead to improved employment outcomes;

5. Creating enhanced statewide collaborations that facilitate the transition process from secondary and post-secondary school, or other pre-vocational training settings, to competitive integrated employment.

\subsection{Utilizing the collective impact model to drive systems change}

NYS has engaged in multiple systems change initiatives over the years, each with varying levels of success. As early as the proposal writing stage of the NYS PIE effort, there was unified agreement that sustainable systems change would not happen quickly; that taking adequate time to build relationships and trust between partners was essential; and that careful coordination across and between the mandated state agencies, which are themselves highly complicated and bureaucratic, necessitated third party involvement.

Several core assumptions were recognized and articulated from the beginning of the project: (1) NYS is large, complex and diverse, and statewide systems change would necessitate engagement and buy-in at the local/regional level; (2) pockets of excellence already existed within the state and were operating successfully within the confines of existing policy, regulations and funding structures; and that these models should be leveraged and scaled up; and (3) a lack of interagency cohesion created a significant barrier to achieving successful outcomes, but that a focus on common goals presented a platform to achieve sustainable systems change.

The NYS PIE project was thus formed and operationalized within a collective impact framework. The collective impact model includes five key elements: a common agenda and approach to solving problems, consistent definitions of what defines success and the collection and sharing of data, a focus on mutually beneficial activities, ongoing and open communication, and the presence of a backbone organization that is tasked with coordinating and facilitating the group (Kania \& Kramer, 2011).

\subsection{NYS PIE project structure}

The Strong Center for Developmental Disabilities (SCDD) at the University of Rochester Medical Center, a University Center for Excellence in Developmental Disabilities (UCEDD), served as the backbone organization for the PIE project, the entity responsible for coordinating and facilitating the tasks of the others within its consortium. A Steering Committee was formed including SCDD and 


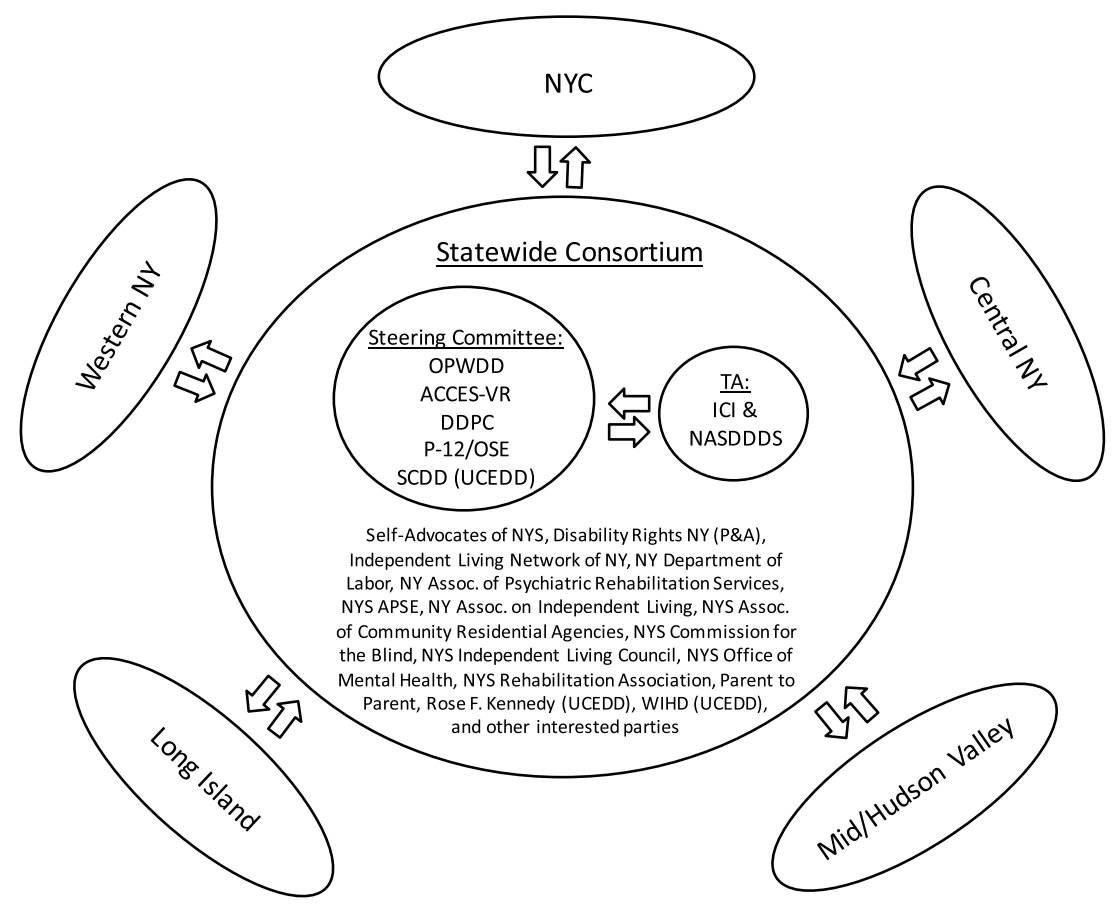

Fig. 1. NYS PIE Project Partners and Structure.

representatives from the key state agencies involved in supporting people with IDD in NYS: The Office for People with Developmental Disabilities (OPWDD), NYS Education Department's Adult Career and Continuing Education Services-Vocational Rehabilitation (ACCES-VR), the Office of Special Education (NYSED P-12/OSE), and the NYS Developmental Disabilities Planning Council (DDPC). The Steering Committee met regularly throughout the 5-year funding period of NYS PIE, beginning with monthly meetings and moving to quarterly meetings as the grant progressed, to ensure that all activities of the project were aligned and properly supported to ensure the achievement of successful outcomes and sustainability beyond the project.

Of critical importance to this effort was the assurance that, as policies and regulations were adjusted to address identified barriers to employment for people with disabilities, the State agencies were informed of the impact of implementation to address any unintended consequences that came from a lack of clarity between intent and interpretation at the local/regional level. As such, the NYS PIE project also engaged a Statewide Consortium representing a wide variety of stakeholder groups for providing guidance to inform the state work plan associated with this effort.

Building and/or increasing the capacity of regional consortia was also a focus of NYS PIE to ensure that systems change took into consideration the diversity of the state, and that associated project deliverables were equitably available. Early in the project, the Steering Committee cross-walked the individual state agencies' regional maps, discovering that there was no consistency in how regional lines were drawn across the various service systems. As a result, the project partners agreed to a 5-region approach for the purposes of engaging local stakeholders, identifying potential locations of pilot demonstration sites associated with the project, and creating bi-directional mechanisms for local/regional and state-level communication and input on the project work plan (Fig. 1). The NYS PIE project benefited from ongoing technical assistance and support from the Institute for Community Inclusion (ICI) at the University of Massachusetts, Boston and the National Association of State Directors of Developmental Disabilities Services (NASDDDS).

\subsection{Project objectives}

The ultimate objective of NYS PIE was to promote Employment First goals and strategies aimed, most specifically, at improving outcomes for youth and young adults with IDD. To accomplish this, the Steering Committee identified a set of mutually beneficial 
focus areas that would guide all activities associated with the NYE PIE effort:

1. Job Readiness: Explore best practices from successful transition-to-work programs in NYS to improve job-readiness curricula for youth and young adults with IDD;

2. Transition from High School to Competitive Employment: Increase the number of students with IDD transitioning from high school to competitive, integrated employment with a concomitant decrease in participation in day habilitation programs and sheltered workshops;

3. Competitive Employment for Young Adults: Increase the numbers of young adults with IDD employed in integrated, competitive employment settings, with emphasis on helping to transition adults from segregated work and day habilitation programs into community-based employment;

4. Sustainable Cross-Agency Collaboration: Establish sustainable cross-agency communication and collaboration at the state and local levels;

5. Improved Resources: Increase and improve information provided to individuals with IDD, parents, educators and school administrators, and other related professionals, with an emphasis on understanding how to access appropriate services in support of obtaining and maintaining competitive, integrated employment;

6. Encourage Additional Partnerships: Engage a wide cross-section of stakeholders including (but not limited to) self-advocates, parents, businesses, adult service providers, the Department of Labor and Office of Mental Health to actively engage in this effort;

7. Create Demonstration Programs: Implement at least eight demonstration programs, which will include Project SEARCH and other transitional employment models, in diverse regions of NYS.

Noting that each state agency used different language and metrics in assessing employment outcomes, the Steering Committee agreed to a common working definition of competitive, integrated employment by which success of the NYS PIE effort would be measured: people with disabilities working a minimum of 20 hours per week at minimum wage or better, and receiving commensurate employer benefits.

\section{Activities and accomplishments}

The efforts of the NYS PIE were directed at enhancing the capacity of the service system to coordinate and utilize available resources more effectively for successful transition from school to work and life in the community. Success of the project was measured against gains in three critical areas: 1) Cross-systems collaboration and capacity building; 2) Policies, processes, and procedures; and 3) Program development and refinement.

\subsection{Enhanced collaboration and capacity building}

The NYS PIE project operated during a time of significant change impacting systems and services for individuals with disabilities at both the federal and state levels. Multiple federal and state-level changes to policy had the potential to plunge the service system into a state of chaos; as state agencies made necessary changes to regulatory guidance, and provider agencies scrambled to adjust their practices to remain in compliance. A primary benefit of the NYS PIE effort was the infrastructure that was built among the State agencies and related stakeholders to enhance communication and collaboration during this time of systems transformation. While some of the state-level systems changes that have taken place over the past five years can be attributed to efforts that pre-date NYS PIE, the structure of the Steering Committee, Statewide Consortium and Regional Consortia associated with this project allowed for enhanced engagement and real time feedback to be incorporated into the decision-making processes as regulatory guidance and dissemination activities were being planned and implemented. Of benefit was the focus on expanding Regional Consortia across the state, building upon an already existing infrastructure of regional collaborative groups that were formed during NYS' Medicaid Infrastructure Grant. NYS PIE staff worked closely with regional NYS Education Department (NYSED) transition coordinators to expand the network of 10-12 existing groups to encompass broader stakeholder representation, and to establish new groups in parts of the state not previously engaged. By the end of the NYS PIE project, 18-20 groups were meeting regularly, operating in both rural and metropolitan areas across all the ten NYSED regions of the state. These groups, often called Transition Collaboratives, include local education agency (LEA) administrators, special educators 
and transition specialists, adult service providers, and regional representatives from NYSED, ACCES-VR, OPWDD, OMH, Parent-to-Parent and other interested stakeholders (self-advocates, business leaders, regional transportation authority representatives, university personnel, etc.).

While the NYS PIE effort was underway, the State (a) was able to leverage PIE dollars to allow NY to become a member of the State Employment Leadership Network (SELN); (b) was awarded a Promoting the Readiness of Minors in Supplemental Social Security Income (PROMISE) grant; (c) received renewed funding via the U.S. Department of Labor's (USDOL) Disability Employment Initiative (DEI); (d) received Medicaid Balancing Incentive Program (BIP) dollars; and (e) became an Employment First State Leadership Mentoring Program (EFLMSP) state through the USDOL-Office of Disability Employment Policy (ODEP). Leadership across these various initiatives, which overlapped in many cases, encouraged collaboration and communication across these parallel and complementary efforts. Through purposeful coordination, NYS leveraged these opportunities to devote targeted attention and resources towards improving employment outcomes for New Yorkers with disabilities, including IDD. NYS not only navigated through significant systems change over the past several years in an effort to align the service system to meet the full intent of the Olmstead v. LC decision (1999) and to address the Centers for Medicare and Medicaid Services requirements outlined in the Home and Community Based Services Final Rule (HCBS, 2014), but also the state is now well positioned to meet the goals associated with full implementation of the Workforce Innovations and Opportunities Act (WIOA).

An additional benefit of NYS PIE is the enhanced relationships and collaboration between the DD Act partners which were further enhanced through this effort. During the later years of the PIE project, the DDPC, UCEDDs, and Disability Rights NY (NY's Protection \& Advocacy agency) collaborated in support of each other's strategic planning efforts in more purposeful ways, ensuring enhanced understanding of mutual goals and synergy in priority setting that will sustain beyond the grant.

The NYS PIE Project also aimed to increase capacity related to self-advocacy across the state. The Self-Advocacy Association of New York State, a NYS PIE Statewide Consortium member, partnered with schools in New York City, Long Island and the Hudson Valley to teach self-advocacy skills in class- rooms. In addition, the Self-Advocacy Association of New York State, the NYS Rehabilitation Association and Disability Rights NY facilitated a series of workshops across the state that focused on promoting self-advocacy skills training for sheltered workshop participants to ensure that the voices of those impacted would be heard throughout the process of workshop transformation. The DDPC and SCDD collaborated on an environmental scan to identify gaps related to self-advocacy across the state. Through this process, it was noted that transition-aged youth were unlikely to engage with existing self-advocacy organizations, whose membership most commonly attracted an older demographic. Furthermore, youth and young adults with IDD lacked the necessary skills to advocate for themselves appropriately both in terms of finding a job and seeking appropriate work related accommodations. It became apparent that there was a need to teach job-related self-advocacy skills as part of transition. As a result, a new curriculum was developed by SCDD staff and an advocate consultant. The curriculum is being piloted in Project SEARCH classrooms during the 2016-2017 school year and will be made more broadly available in Fall 2017.

Finally, both Steering Committee and Statewide Consortium partners noted the need to elevate the quality of job development and job coaching supports across the state. To address this, the NYS PIE project funded NYS APSE, a Statewide Consortium member, to offer the Certified Employment Specialist Professional (CESP) exam to qualified individuals free of charge in conjunction with the NYS APSE annual conferences in 2015 and 2016. At the start of the NYS PIE effort, there were only four CESPs in the state. Because of this effort, there were 67 CESPs at the completion of NYS PIE, and NYS APSE had committed to continuing to support the initiative moving forward.

\subsection{Systems change accomplishments: Policy, processes and procedures}

Various systems-level changes took place, within a relatively short timeframe, across the various state agencies in NYS that support individuals with intellectual and developmental disabilities. In addition to supporting communication and coordination through the Steering Committee and Statewide Consortium, the NYS PIE project prioritized and funded activities which focused on providing necessary technical assistance and information dissemination at the local 
and regional level in support of successful implementation of these changes.

\subsubsection{Developmental disabilities and Medicaid}

Beginning in 2012, OPWDD embarked on a comprehensive system-wide transformation effort prompted by a planned shift to managed care and the need to ensure that the state's 1915(c) waiver was in compliance with the Centers for Medicare and Medicaid Services's Home and Community Based Services final settings rule. NYS PIE funding allowed for the opportunity for OPWDD to receive targeted technical support through the SELN during this transition.

In May 2014, the final approved NY Plan to Increase Competitive Employment Opportunities for People with Developmental Disabilities was made public, which identified the following as priority areas: (1) increase the number of individuals engaged in competitive employment, (2) increase the number of students that transition from high school to competitive employment; (3) collaborate with the educational system to ensure that stakeholders are aware of employment services; and (4) transition workshop participants to competitive employment or other meaningful community activities (OPWDD, 2014). In March 2015, several NYS PIE Statewide Consortia members were appointed to the Commissioner's Transformation Panel, including a self-advocate. The Panel was charged with developing a set of recommendations that would inform the final implementation plan, and listening sessions began to take place across the state. NYS PIE Consortia members mobilized to encourage the participation of a broad group of stakeholders in these sessions, to provide input into the process; with the state independent living centers and the Self-Advocacy Association of New York State playing a leading role in mobilizing individuals and families to engage in the process.

OPWDD placed considerable emphasis on shifting services towards integrated settings in accordance with the HCBS Final Rule. This included statewide planning for the transformation and eventual closure of the Medicaid funded sheltered workshop system, as well as rate restructuring to incentivize supported employment services. As of 2013, no new entries into the sheltered workshop system would be allowed. Furthermore, OPWDD set a 6-year timeline for the closure/redesign of segregated, workshop-based pre-vocational services. In early 2015, OPWDD published a Work Settings Report, which was based in part on the recommendations of the Transformation Panel (OPWDD, 2015). The NYS PIE project played a supportive role in this process, providing technical assistance and information dissemination via both the Statewide and Regional Consortia. This plan gave providers a deadline of January 2017 to submit a formal business proposal for transforming or closing workshops across the state. NYS PIE funding was leveraged by the NYS Rehabilitation Association to develop and implement an intensive technical assistance pilot initiative aimed at assisting twelve provider agencies with tools and resources to assist in developing new business models in support of the shift to a community-based employment service delivery system. These tools have since been moved to a web-based platform and made available to any provider across the state (http://nyrehab.org/NYSRA_Transformation_2.0).

OPWDD leveraged supports from the NYS PIE project to pilot the expansion of their Employment Training Program (ETP), a career discovery-based service that provides stipends for trial work experiences to high school students. ETP interns typically work between 4 and 12 hours per week, and are paid by NYS at minimum wage or better based on the internship placement. Interns are also required to attend classes that enhance work skills. A complementary work-readiness curriculum was developed through NYS PIE, and has been implemented across the state in collaboration with NYSED P-12/OSE. The curriculum contains six modules focused on career discovery, community involvement, employer expectations, job development, professional behavior and job retention. The curriculum has been made available for free online (https://www. humanservicesed.org/Default.aspx?RD=4315), and NYS PIE supported regional curriculum trainings for transition teachers across the state.

Finally, OPWDD launched a new pre-employment service in 2014 called Pathway to Employment, a short-term service which aims to deliver personcentered planning and supports towards the outcome of competitive employment or self-employment. A secondary goal of the Pathway service was to improve communication between OPWDD and ACCES-VR related to services for people with IDD, which was a goal identified by the Steering Committee early in the NYS PIE effort. A requirement of the Pathway service is the creation of a Discovery Report, which is to be submitted to ACCES-VR to promote cross-systems planning and coordination of services to support individuals along their path to employ- 
ment. Leveraging additional funding from DDPC, OPWDD contracted with SCDD to conduct a process and outcomes evaluation of the Pathway service. To date, over 1,200 individuals have participated in the service, with the majority coming from day habilitation programs (40\%) or sheltered workshops (18\%). Currently, there is an $82 \%$ compliance rate associated with the submission of the Discovery Report to ACCES-VR, although compliance has steadily increased over the past year as provider agencies have become more comfortable with implementation of the service.

\subsubsection{Vocational rehabilitation}

ACCES-VR has similarly engaged in significant systems change during the NYS PIE project, including a shift from an hourly to a milestone payment model for supported employment. At the start of the PIE project, it was noted that there was a common perception across the state that ACCES-VR could not provide funding supports for students while they were still in high school. However, during Year 1 of PIE, via an intensive cross-systems policy and regulatory analysis completed by the NYS protection and advocacy agency on behalf of the project, it was acknowledged that this was not an accurate interpretation of existing policy (Commission on Quality of Care and Advocacy for Persons with Disabilities, 2012). An early action of the NYS PIE project was to assist ACCES-VR in clarifying this across the state, using the Regional Consortia as a platform to disseminate accurate guidance to the provider community. NYS PIE pilot projects, which included replication of Project SEARCH, further supported consistency in practice across the state, as regional VR offices were engaged in approving funding for the job coaching component of these transition-to-work programs.

The transition-aged youth focus on the NYS PIE project afforded time and attention for ACCES-VR to create an infrastructure and capacity necessary to fully implement WIOA. Throughout the PIE project, ACCES-VR aimed to develop statewide initiatives focused on ensuring equity and consistency across the state. ACCES-VR prioritized vocational supports for transition-aged youth through the inclusion of Youth Employment Services in its Core Rehabilitation Services (CRS) contracts, which went into effect on January 1, 2014. In the new CRS contracts, ACCES-VR identified a menu of reimbursable and evidence-based Youth Employment Services, aimed at improving employment outcomes for youth. As a result, the number of community rehabilitation providers (CRP) approved to provide services to transition-aged youth significantly increased. However, despite an increase in demand for Youth Employment Services, the overall ACCES-VR budget remained flat across the years of the NYS PIE project. Thus, while many agencies were approved to provide Youth Employment Services, there were often not dollars attached to the CRPs' contracts within those service lines. ACCES-VR has been actively engaged in reviewing overall capacity with the intent of adding additional dollars to agencies who have been approved to provide Youth Employment Services.

Also in 2014, ACCES-VR launched the Transition and Youth Services team (TAYS). The TAYS team consists of a Statewide Manager and 15 Senior Vocational Rehabilitation Counselors, one assigned to each ACCES-VR District Office across the state, with both statewide and local/regional responsibilities. The initial design was relatively broad and was developed prior to, but in anticipation of, WIOA. The team is specifically charged to work with youth under the age of 25, and quickly developed and implemented a consistent and statewide high school referral process across all regions of the state. Since the TAYS team was established, ACCES-VR observed an increase of individuals under the age of 25 entering the VR system. When NYS PIE began in 2011, transition-aged youth represented $45 \%$ of the statewide caseload. By the end of NYS PIE in 2016, this percentage increased to over $50 \%$

To further support the transition-to-work effort and expand its reach, ACCES-VR released a request for proposals to procure Community Employment Specialists (CES) services to provide consultant-based technical assistance from community rehabilitation providers within LEAs to inform school personnel on student eligibility requirements and availability of VR services to eligible youth. An additional goal of the CES was to provide strategies for shifting the goals and activities included on the school-based Individual Education Program (IEP) into appropriate goals for the purposes of the Individualized Plan for Employment (IPE). The CES team began operating during the 2014-2015 school year. Currently, there are 31 members of the CES team, with a minimum of three Specialists located in each of ACCES-VR's ten regions across the state. After the first year of implementation, ACCES-VR noted increased informed referrals of high school students with more significant disabilities, and earlier connections between potentially eligible students and VR counselors. Both 
the CES and TAYS teams have been engaged in the Regional Consortia, and the TAYS Statewide Manager became a member of the NYS PIE Steering Committee during the final two years of the grant.

\subsubsection{Special education}

At the start of the NYS PIE project, the IEP diploma was the standard exiting certificate offered to students with disabilities as an alternative to a regular high school diploma. However, the IEP diploma served primarily as a certificate of attendance and meeting the goals on a student's IEP. Additionally, despite the name, the certificate was not a recognized diploma. This created much confusion for individuals and families who were often surprised to be denied access to post-school activities requiring a high school diploma, such as entrance into postsecondary programs and the military.

In 2013, NYSED P-12/OSE began to phase in two new exiting credentials for students with disabilities. These include the Career Development and Occupational Studies (CDOS) Credential (http://www.p12.nysed.gov/specialed/publications/ CDOScredential-memo-613.htm) and the Skills and Achievement Commencement Credential (http://www.p12.nysed.gov/specialed/publications/ SACCmemo.htm; only available for students with significant disabilities who are eligible to take the NYS Alternate Assessment). Both credentials placed an increased emphasis on career readiness training. The CDOS Credential requires the development of a career plan and completion of a minimum of 54 hours of work-based learning, preferably to take place in the business community. Implementation of the new credentials required significant technical assistance and training, and the Statewide and Regional Consortia played a role in assisting in the implementation process. NYSED's regional transition specialists, housed in the Regional Special Education Technical Assistance Support Centers across the state, leveraged the Transition Collaboratives as a mechanism for disseminating information and clarifying emerging NYSED policies and guidance, as well as to collect real-time feedback on the progress of implementation at the local level. This feedback framed the topics and frequency of the ongoing technical assistance opportunities provided by the Regional Special Education Technical Assistance Support Centers across the state.

However, concerns regarding the credentials were raised in two specific areas: (a) lack of awareness of the credential within the business community, thus minimizing its impact as an indicator of a student's readiness to enter the workforce, and (b) the credential was only initially made available to students with disabilities, thus bypassing an individual's right to choose to disclose their disability status when applying for jobs. Based in part on feedback from the Transition Collaboratives across the state and collected during an open comment period, NYSED revised the structure of the CDOS Credential in 2016, making it available to all students either as a complement to or in place of a regular diploma. Furthermore, it was clarified that alternately assessed students are also eligible to obtain the CDOS Credential if they meet the requirements, which provided an avenue for students with the most significant disabilities to engage in quality work readiness preparation with the goal of employment as part of their high school curriculum.

Implementation of the CDOS Credential continues to be a challenge. Data reported by NYSED for the 2015-2016 school year, the last year of the PIE project, indicated that only 2,036 students with disabilities exited school with a CDOS Credential, with 715 receiving it as their only exiting credential. An additional 1,321 received it as a supplement to a regular high school diploma (NYSED, personal communication, 2016). The remainder of students with disabilities who did not meet the requirements of the CDOS Credential were presented with a certificate of attendance. The NYSED regional transition specialists continue to provide ongoing technical assistance across NYS to assist schools in providing meaningful work readiness preparation for students with disabilities. Specific emphasis has been placed on helping districts comply with the workbased learning requirements of the CDOS Credential, including strategies to engage the business community to offer community-based work experiences. Project SEARCH has been reaffirmed as a promising practice in NYS, as the model meets the requirements of the CDOS Credential.

To meet the demands for technical assistance across the state, NYSED P-12/OSE devoted additional IDEA resources to expand its technical assistance resources through the RSE-TASC, increasing the number of transition specialists from 16 to 25 . The expansion of the regional transition specialist team allows for an increased capacity to provide supports and training to school districts on quality transition programs and services, instruction toward the CDOS learning standards, including students with disabilities in CTE courses, and engaging and supporting stu- 
dents in meaningful work-based learning programs in community settings. Additionally, the regional transition specialists have established partnerships with ACCES-VR's TAYS and CES teams across the state to coordinate efforts within the regions.

\subsubsection{Employment first}

Given the complexity of NYS, the establishment of an Employment First policy was beyond the scope of a 5-year systems change effort. However, the NYS PIE project made the promotion of an Employment First philosophy a specific goal. In September 2014, Governor Andrew Cuomo signed Executive Order No. 136 (NYS, 2014), which established the NYS Employment First (E1) Commission, which was tasked with developing recommendations for the development of an Employment First Policy in NYS. The E1 Commission brought together high level leadership across all state agencies associated with providing employment and workforce development services and supports. One of the first activities of the E1 Commission was to embark on a statewide listening tour to gather feedback from relevant stakeholders. Members of the NYS PIE Steering Committee and Statewide Consortium were actively engaged in providing testimony to the E1 Commission as part of this process. Additionally, the NYS PIE infrastructure of the Statewide Consortium allowed for enhanced communication between partners that did not previously exist, and provided a forum to ensure coordinated and consistent messaging throughout the public comment period. In March 2015, the E1 Commission released its final Report and Recommendations (2015), which was informed by existing initiatives already taking place within the state, including the NYS PIE, PROMISE and DEI projects. The New York Employment Services System (NYESS) leadership team, which also has responsibility for the NYS PROMISE project and participated on the NYS PIE Statewide Consortium, was tasked with spearheading the effort into the implementation phase.

During the final year of NYS PIE, as the focus of the effort shifted to sustainability of the activities associated with the project, NYS PIE and NYS PROMISE project leadership partnered to submit a successful application to become an US DOL-ODEP EFSLMP state, with the specific objective of working towards implementation of several goals outlined in the E1 Commission report that closely aligned with the PIE and PROMISE initiatives. Broadly, these fell into the categories of (1) modeling the hiring of people with disabilities in state agencies, providers and contractors that receive state funding, and (2) offering cultural training on Employment First to all direct support professionals to raise expectations. Additionally, through the EFSLMP Vision Quest process, NYS continued work on developing a unified approach to referral, assessment and intake across the following systems: OPWDD, ACCES-VR, OMH, DOL. A subcommittee of the E1 Commission has been formed to work on this initiative, which is specifically focused on improving cross-systems coordination in support of transition-age youth who are entering the adult service system. This effort has empowered the Inclusive Workforce Alliance (IWA), a consortium representing 29 provider trade associations in NYS, to engage around Employment First implementation. In addition to serving in an advisory capacity to the E1 Commission, the IWA is taking the lead in implementing a statewide capacity building effort focused on the provider culture change that is necessary to successfully shift the services system away from the historically disproportionate delivery of segregated day habilitation and sheltered workshop programs. This work was a natural extension to the transformation project developed and implemented by the NYS Rehabilitation Association through the combined efforts of NYS PIE and NY's BIP project.

Finally, in December 2015, Our Ability Alliance officially established the New York Business Leadership Network, a statewide network of businesses interested in employing people with disabilities. This was a direct result of Executive Order \#136, which called for 100 businesses to commit to formal policies to hire people with disabilities as a part of their business strategy.

\subsection{Program development and key project deliverables}

\subsubsection{Pilot projects}

The coordination and expansion of Project SEARCH in NYS was a purposeful focus of the PIE effort due to the required collaboration of schools, CRPs, business, ACCES-VR and OPWDD indicated by the program model (Daston, Riehle \& Rutkowski, 2012). Additionally, as discussed previously, it was through replication of Project SEARCH that VR's role in funding job coaching supports for high school transition programs was initially tested. When NYS PIE began, there were four high school Project SEARCH programs in operation, all in Western and Central NY. By the end of the project, there were 
Table 1

Project SEARCH expansion and project outcomes by year

\begin{tabular}{lccc}
\hline NYS PIE Project Year & \# Programs in Operation & Completion Rate & Employment Rate \\
\hline Y1 & 4 & $88 \%$ & $67 \%$ \\
Y2 & 9 & $96 \%$ & $59 \%$ \\
Y3 & 11 & $91 \%$ & $62 \%$ \\
Y4 & 13 & $88 \%$ & $63 \%$ \\
Y5 & 15 & $83 \%$ & $62 \%$ \\
\hline
\end{tabular}

16 Project SEARCH sites operating across the state (Table 1), 7 of which were pilot programs associated with NYS PIE. This included four adult programs, including one pilot that adapted the Project SEARCH model to move individuals out of a sheltered workshop into community employment opportunities.

The NYS PIE work plan called for a minimum of one pilot project to be in each of the five regions of the state (Fig. 1). The Steering Committee selected the location of the pilot sites, and priority was given to locations where there were not strong cross-systems partnerships. Thus, the Project SEARCH programs became a "living laboratory" for building relationships across the systems at a local level. In some areas, such as Long Island, a request for proposals was issued within a specified geography, and the Steering Committee made final selections of the partners associated with a pilot. In other parts of the state, however, existing relationships were leveraged and partners were selected based on capacity and availability of funding within a region.

Over the course of NYS PIE, 396 students completed Project SEARCH, with 247 (62\%) transitioning into competitive jobs in the community working a minimum of 20 hours per week at minimum wage or better. SCDD, as the NYS coordinator of Project SEARCH, collected and analyzed longitudinal outcome data to better assess the long-term impact of the model in preparing youth not only to enter the work force, but to remain engaged over time. As part of the NYS PIE project, a 5-year longitudinal evaluation of outcomes from three Project SEARCH programs that were already in operation at the start of the NYS PIE program was completed and submitted for publication. Prior to publication, the analysis of data was shared and discussed with the Steering Committee. Of interest was that the job retention rate was nearly double for Project SEARCH graduates at every time point in comparison to outcomes reported by OPWDD. Additionally, the study noted that long-term outcomes were dramatically higher for those program graduates who were hired by a Project SEARCH host business. In fact, job retention dropped off after 30 months for all participants who were hired elsewhere in the community (Christensen, Hetherington, Daston \& Riehle, 2015).

During the final two years of the NYS PIE effort, prompted by OPWDD's announcement regarding the impending transformation of the sheltered workshop system, the PIE project team piloted an adaptation of the Project SEARCH model aimed at transitioning individuals out of the workshop and into competitive, integrated employment. The pilot served 10 participants, with only 8 completing the program, so results are limited. However, the pilot achieved some level of success, with 5 participants (63\% of program completers) making a successful transition to community-based employment. It is worth noting that successful transition did not appear to be related to the age of the participant or a history of unsuccessful attempts at community-based employment in the past. Instead, positive outcomes appeared to be associated with the time spent in the sheltered workshop setting prior to engaging in Project SEARCH. None of the program participants who had been in the workshop for more than 5 years made a successful transition, while all participants who had been in the workshop for less than 5 years obtained competitive employment upon program completion. Results of this evaluation have been shared with program partners, presented at multiple professional conferences, and were recently submitted for publication (Christensen \& Richardson, 2017).

Project SEARCH outcome data was collected as part of the NYS PIE project evaluation activities. However, ACCES-VR and OPWDD, the primary funders of job coaching and development services provided in these programs, expressed a desire for ongoing access to outcome data beyond the PIE project. During the final year of NYS PIE, grant funds were leveraged to build capacity within the existing NYESS database to track employment outcomes of all Project SEARCH sites across NYS moving forward. Project SEARCH teams were provided targeted technical assistance to support data entry beginning with the 2015-2016 school year. 


\subsubsection{MyPathNY.org}

In the early months of the NYS PIE effort, the focus of discussion among the Steering Committee centered on the need to develop a cross-systems tool that would simplify both access to information and connections to appropriate services and supports. The state agencies recognized that there was much confusion about what each agency offered, and that the processes of eligibility determination were complex and often overwhelming for families. To address this, the Steering Committee envisioned a single tool that would provide up-to-date information and would assist in guiding individuals and families to the most appropriate service system(s) to meet their needs. A cross-systems workgroup was formed to provide input on this project. The workgroup met regularly during the first three years of the PIE project, and mapped out multiple scenarios for what successful transition to employment should look like, taking into consideration the regulatory requirements of each individual system. Over the years of NYS PIE, the tool took on many forms, beginning as a simple online resource guide. However, in response to ongoing feedback from the Statewide and Regional Consortia, the vision for MyPathNY.org was conceptualized.

Designed to be used by youth and young adults with IDD and other disabilities, MyPathNY.org is a free website aimed to help all NYS students and young adults with disabilities navigate their individual path towards competitive, integrated employment. MyPathNY.org presents users with a series of simple, multiple choice questions. The site analyzes responses and assesses an individual's current knowledge and experiences, and then creates a personalized report outlining recommended next steps to support the individual's path to employment. The intent of MyPathNY.org is to connect users to the most appropriate agency and services that will best support their self-determined goals. The site makes suggestions for the types of questions to ask and the information the individual should be prepared to provide when first connecting with an agency. An accompanying folder serves as a repository for individuals to collect and store their important documentation, such as their IEP and resume. For example, if the recommendation is to seek eligibility for services with vocational rehabilitation (VR), the site will provide contact information for the nearest local/regional office, a list of necessary documentation that is required, and offer a list of questions to consider before meeting with a VR counselor.
MyPathNY.org includes four user sessions:

1. Getting Connected: By answering a series of questions, users find out where to go and who to talk to get started, based on their experience to date. The steps in each report outline how to connect with people and resources in NYS to move from school and other settings to a paying job. If the user is blind or visually impaired, the site connects them to the New York State Commission for the Blind. All others are connected to ACCES-VR, and to OPWDD* as appropriate.

2. Preparing for Work: The questions in this session result in a report that provides information users will need when they decide it's time to find a job. Users will learn what goes into a resume, why references are important and how to prepare for job interviews.

3. The Partners on Your Path: This session starts with an introduction to important state agencies that can work together to help young adults with disabilities on their path to employment. This series of questions help users identify services available through the state agencies that can help them on their path to employment, such as assistive technology and transportation training.

4. Working Has Benefits: This session includes a dream board sequence, information on financial literacy and benefits planning, and concludes with an overall review of the individual's employment readiness. There is an interactive Working Has Benefits Calculator that performs a simple calculation of the impact of work on SSI income.

*NOTE: The site will soon incorporate information about the Office of Mental Health (OMH).

Based on feedback from user testing of the website, MyPathNY.org has been determined to be best used as a tool for professionals working alongside transitionaged youth and young adults. Subsequently, the site has been marketed across the state to transition teachers, Medicaid Service Coordinators, VR counselors and parent network groups via direct mail and through various targeted webinars and conference presentations,. The site has been quickly embraced and to date, over 6,600 folders have been requested and disseminated.

During the Summer of 2016, MyPathNY.org was presented to the E1 Commission workgroup. It was agreed that the site meets many of the same systems' coordination goals that the workgroup was seeking to address. As a result, the E1 Commission has for- 
mally endorsed the website and is promoting the tool across all state agencies that provide employment and workforce development supports.

\section{Lessons learned and next steps}

While significant progress has been made over the past five years, there is still much work to be done to achieve the goal of ensuring that all New Yorkers with disabilities, including IDD, have a pathway to competitive, integrated employment. During the final months of NYS PIE, the Steering Committee and Statewide Consortium met to reflect on the progress of the PIE initiative. Additionally, the Consortium identified unresolved barriers to successful employment outcomes, including new barriers that may have emerged as unintended consequences of changes in policy and regulatory practice over the life of the project. An action plan was developed outlining next steps for systems change efforts and plans for sustaining the work beyond the grant funding period.

The DD Act Network Partners (SCDD/UCEDD, DD Planning Council and the Protection \& Advocacy agency) have committed to sharing responsibility for sustaining the Statewide Consortium, and will continue to convene the group on a quarterly basis. The Steering Committee and Statewide Consortium reaffirmed the importance of fully utilizing the NYESS system to ensure that quality outcome data is collected and shared to assess progress and inform further efforts to transform the service system and associated funding mechanisms in support of Employment First outcomes. Additionally, the NYESS system is expanding functionality to track employment outcomes of statewide transition-towork initiatives, such as Project SEARCH, to assess the long-term impact of these models.

Through the continued work of the Employment First Commission, efforts are underway to identify shared assessment tools and develop coordinated eligibility processes that will streamline access to the most appropriate services and supports for job seekers with disabilities, regardless of which state agency system they initially engage with. Continued supports will also be provided to CRPs as the state continues to shift away from an overreliance on segregated employment and non-work services.

As noted previously, the collective impact model served as a successful framework for approaching the work of the NYS PIE initiative. Project partners specifically pointed to several key elements of the collective impact approach as particularly valuable, including identifying a common agenda (to increase employment outcomes for youth and young adults with IDD); focusing on mutually beneficial activities (expansion of the Project SEARCH and high school ETP models); the development of a shared definition of competitive, integrated employment (working 20 hours or more per week, at minimum wage or better, in the community); and having consistent opportunities for open communication and information sharing throughout the project (via the Statewide and Regional Consortia). Additionally, the role of the UCEDD as the backbone entity coordinating the project was noted by both the Statewide Consortium and the Steering Committee as vital to maintaining momentum throughout the project. This became especially important as shifts in individual state agency priorities had the potential to pull the effort off track from the overarching PIE focus on cross-systems solutions to identified barriers.

\section{Acknowledgments}

The NYS PIE project, a Project of National Significance funded by the Administration on Intellectual and Developmental Disabilities, was a collaboration of over 100 organizations and agencies across New York who participated at the state, regional and/or local levels. The coordination team is especially grateful for the contributions of Frank Coco, Pat Dowse, Alan Gallagher, Peter Herrig, Steve Holmes, James Huban, Andrew Karhan, Anna Lobosco, Gerri Malone, Sophie McDermott, Don McManus, Ceylane Meyers-Ruff, Jennifer Monthie, Patrick Pascarella, Clint Perrin, Amy Steiner, Lynne Thibdeau and Lisa VanRyn.

\section{Conflict of interest}

None to report.

\section{References}

Christensen, J. J., Hetherington, S., Daston, M., \& Riehle, E. (2015). Longitudinal outcomes of Project SEARCH in Upstate New York. Journal of Vocational Rehabilitation, 42(3), 247255.

Christensen, J. J. \& Richardson, K. (2017). Project SEARCH workshop to work: Participant reflections on the journey through career discovery. Journal of Vocational Rehabilitation, 46(3), 341-354. 
Commission on Quality of Care and Advocacy for Persons with Disabilities. (2012). New York State facilitators and barriers to competitive, integrated employment for youth with intellectual and developmental disabilities, interim final report. Unpublished report.

Daston, M., Riehle, J. E., \& Rutkowski, S. (2012). High school transition that works: Lessons learned from Project SEARCH. Baltimore, MD: Brooks Publishing.

Home and Community-Based Setting Requirements for Community First Choice and Home and Community-Based Services (HCBS) Waivers; Final Rule, 79 Fed. Reg. 2947 (January 16, 2014) (amending 42 CFR Pt 430, 431 et al.).

Kania, J., \& Kramer, M. (2011). Collective impact. Stanford Social Innovation Review, Winter 2011, Retrieved December 23, 2016 from https://ssir.org/images/articles/ 2011_WI_Feature_Kania.pdf

New York State. (2014). Executive Order No. 136: Establishing the New York Employment First initiative to increase employment of New Yorkers with disabilities. Retrieved December 23, 2016 from https://www.governor.ny.gov/news/no-136establishing-new-york-employment-first-initiative-increaseemployment-new-yorkers

New York State Employment First Commission. (2015). Report and recommendations. Retrieved December 23, 2016 from http://www.nyess.ny.gov/docs/Employment_First_March 2015_final.pdf

Office for People with Developmental Disabilities. (2014). New York plan to increase competitive employment opportunities for people with developmental disabilities. Retrieved December 23, 2016 from https://opwdd.ny.gov/sites/default/ files/documents/draft-plan-increase-employment-opps.pdf

Office for People with Developmental Disabilities. (2015). Work settings report. Retrieved December 23, 2016 from https:// opwdd.ny.gov/opwdd_about/commissioners_page/work_settin gs_plan

Olmstead v. LC, 527 U.S. 581 (1999).

Rehabilitation Research and Training Center on Disability Statistics and Demographics. (2009) Annual Disability Statistics Compendium: 2009. Retrieved December 23, 2016 from https://disabilitycompendium.org/sites/default/files/useruploads/Archives/PreviousDisabilityCompendiumReleases/ 2009\%20Compendium\%20Release\%20r.pdf

Von Schrader, S., Erickson, W., Vilhuber, L., \& Golden, T. P. (2010). New York State disability and employment status report: 2009. Ithaca, NY: Cornell University, Employment and Disability Institute. 